\title{
The Right to be Forgotten in the post-Snowden era
}

\section{Paul Bernal1}

This piece was first published in Privacy In Germany in their $5^{\text {th }}$ issue of 2014, available online here:

http://www.pingdigital.de/ce/the-right-to-be-forgotten-in-the-post-snowdenera/detail.html

This version of the piece is published with the permission of Privacy in Germany.

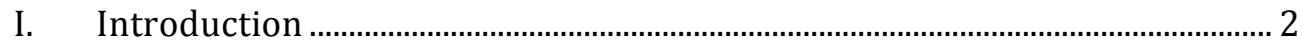

$1 \quad$ Data Protection Reform....................................................................... 2

2 The possible impact of Snowden and Google Spain combined ........ 3

II. What is the right to be forgotten? ........................................................................ 4

$1 \quad$ Data or stories - and 'forgetting' or erasure? …………….................... 5

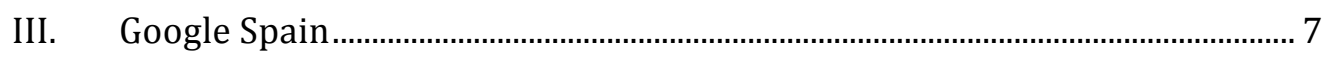

1 Academic shockwaves from Google Spain .............................................. 8

2 Google's response to the Google Spain ruling.....................................10

IV. Google Spain in the context of Snowden .........................................................11

1 Courts showing more privacy-awareness.............................................11

2 Links between authorities and commercial organisations..............12

3 Contrasting the Google Spain and Snowden issues............................13

V. The Right to be Forgotten in the post-Snowden era........................................14

1 Workable solutions and meeting the challenges................................15

2 Data Protection Reform........................................................................17

${ }^{1}$ Dr. Paul Bernal is a Lecturer in Information Technology, Intellectual Property and Media Law at UEA Law School, the University of East Anglia. 


\section{Introduction}

The revelations of Edward Snowden of at least part of the true extent of the gathering and processing of communications data by the intelligence services of many nations, most notably the US and the UK, sent shockwaves through the Internet, not least amongst those concerned with privacy. Though the information revealed relates primarily to government surveillance, the ramifications are far wider and far greater than that. It is hard to find a privacyrelated issue that has not been affected by them. The behaviour and actions of people, businesses, governments and courts have all seen changes, and those changes have an impact.

The right to be forgotten is one of those issues: it may seem to have nothing to do with government surveillance but there are both direct and indirect connections between the two. The Snowden revelations have had an impact on how we understand the right to be forgotten, how the right to be forgotten is being implemented, and how we might find an appropriate future for it.

\section{Data Protection reform}

The right to be forgotten has been the subject of much discussion since it was first mooted as a key part of the reform of the European data protection regime. The progress of the reform has been complex and contentious, and the right to be forgotten has been one of the bones of contention all the way through. Some of the early arguments about it have been extreme - including suggestions from American academics that the right to be forgotten 'represents the biggest threat to free speech on the Internet in the coming decade'2 or describing it as ' $[\mathrm{m}]$ ore crap from the EU'. ${ }^{3}$ These kinds of suggestions were accompanied by a significant lobbying effort by Google. Their Global Privacy Counsel, Peter Fleischer, has also blogged extensively on the subject. ${ }^{4}$ In early 2014, Fleischer declared that the 'old' draft of the Data Protection Regulation was 'dead' and would have to be rewritten. ${ }^{5}$ Part of that rewrite, Fleischer seemed to be implying, would be a recasting or even removal of the right to be forgotten. ${ }^{6}$

\footnotetext{
2 Rosen, Stanford Law Review Online, available at http://www.stanfordlawreview.org/online/privacy-paradox/right-to-be-forgotten.

${ }_{3}^{3}$ Bambauer, Harvard's Info/Law blog, available at http://blogs.law.harvard.edu/infolaw/2012/01/25/more-crap-from-the-e-u/.

${ }^{4}$ Fleischer makes it clear that the blogs represent his own views, not those of Google. He has written on the subject many times, e.g. 'Foggy thinking about the right to oblivion' in March 2011(http://peterfleischer.blogspot.co.uk/2011/03/foggy-thinking-about-rightto-oblivion.html) '"The Right to be Forgotten", seen from Spain' in September 2011 (http://peterfleischer.blogspot.co.uk/2011/09/right-to-be-forgotten-seen-fromspain.html) 'The right to be forgotten, or how to edit your history' in January 2012 (http://peterfleischer.blogspot.co.uk/2012/01/right-to-be-forgotten-or-how-toedit.html), 'Don Quixote' (about the whole reform process) in February 2013 (http://peterfleischer.blogspot.co.uk/2013/02/dox-quixote.html).

${ }_{5}$ Available at http://peterfleischer.blogspot.co.uk/2014/01/turning-our-backs-on2013.html.

${ }^{6}$ The conflict between the EU and the US over the right to be forgotten is examined in Bernal, 'The EU, the US and the Right to be Forgotten', in Serge Gutwirth, Paul De Hert, and Ronald Leenes (eds.), Computers, privacy and data protection- reloading data protection, 2014.
} 
EU regulators pressed on with the right to be forgotten regardless, and though its form has changed a little, as has its name, to include the word 'erasure', it is still a crucial part of the proposed reform. In May 2014 another critical event happened that has made that discussion more pertinent and that dispute more pointed: the ruling by the CJEU in the 'Google Spain case'7 that, regardless of the reform process, a form of the right to be forgotten already exists at least in relation to search engines. It is at least possible that the outcome of the case was influenced by the attitude of courts to privacy in the post-Snowden era.

\section{The possible impact of Snowden and Google Spain combined}

The combination of the two events has forced upon governments, businesses, academics and advocates a reassessment of what the right to be forgotten could and should mean, whether there is any need for it or any purpose to it - and what the consequences of its existence might or might not be.

In some ways what Snowden uncovered makes the idea of a right to be forgotten seem pointless: what is the point of asking for anything on the Internet to be erased or made inaccessible if secret archives of our every activity are been made, and made accessible, by a wide range of authorities? Conversely, the knowledge that the level of surveillance on activities on the Internet is vastly greater than any but the most active conspiracy theorists might have imagined adds an urgency and deeper significance to the need for real and permanent deletion of data - and for a drive towards business models based on less extensive data gathering. If we wish for more privacy, for more protection from the excesses of those performing surveillance, the first step is for commercial entities to hold less data about us - for data minimisation to be paid more than just lip service. Encouraging business models that embrace data minimisation, as has been argued before, is one of the key purposes of the erasure aspect of the right to be forgotten.

Further, if Google Spain indicates that the right to be forgotten already exists, is there any point in those that oppose the idea of the right continuing to fight it? Should they accept the right, and simply try to find the best way to implement it - or should they take a new position, and work harder to bring forward the reform of the data protection regime, but ensure that the new regime specifically excludes the right to be forgotten, or sets it out in such a weak form as to be effectively meaningless?

So which is it? Does the post-Snowden era demand a stronger embrace of the right to be forgotten, or suggest a new pragmatism in which such a right has no place? It is time to reassess what we might want from such a right, and whether in the post-Snowden environment such a right might even be possible. The timing is crucial: the combination of the revelations of Snowden, the Google Spain judgment and the on-going reform of the data protection regime provides a unique opportunity to try to get it right.

With an apparently increasing level of interest in privacy by the courts, and more willingness from those courts to make bold decisions with far-reaching consequences, it seems as though some kind of right to be forgotten will be with

${ }^{7}$ Case C-131/12, Google Spain SL, Google Inc. v Agencia Española de Protección de Datos (AEPD), Mario Costeja González. 
us for the foreseeable future. The question is what form that right will take - a particularly pertinent question given that right now it appears unclear what a 'right to be forgotten' actually means. What are the differences between a right to be forgotten and a right to erasure? What does the Google Spain ruling imply and how does the current form of a right to erasure, as set out in the most recent draft of the General Data Protection Regulation, fit with it?

This article will attempt to answer these questions and make this situation clearer. It will look at what kind of rights are needed, and how they might come into action. It will argue that the need for a right to be forgotten, appropriately limited and balanced, has become more intense. Ensuring that the data protection reform happens, quickly but carefully, has become more urgent.

\section{What is the right to be forgotten?}

The idea of a right to be forgotten has been discussed so much, particularly since the ruling in the Google Spain case, that it is sometimes difficult to be sure what is meant by the term. The first place to start from is the draft of the General Data Protection Regulation - though it must be remembered that the regulation has not yet been agreed, and in the light of the Google Spain ruling there may be intense, late lobbying to change the wording and the meaning.

\section{Article 17:Right to be forgotten and to erasure}

1. The data subject shall have the right to obtain from the controller the erasure of personal data relating to them and the abstention from further dissemination of such data, especially in relation to personal data which are made available by the data subject while he or she was a child, where one of the following grounds applies:

(a) the data are no longer necessary in relation to the purposes for which they were collected or otherwise processed;

(b) the data subject withdraws consent on which the processing is based according to point (a) of Article 6(1), or when the storage period consented to has expired, and where there is no other legal ground for the processing of the data;

(c) the data subject objects to the processing of personal data pursuant to Article 19;

(d) the processing of the data does not comply with this Regulation for other reasons.

2. Where the controller referred to in paragraph 1 has made the personal data public, it shall take all reasonable steps, including technical measures, in relation to data for the publication of which the controller is responsible, to inform third parties which are processing such data, that a data subject requests them to erase any links to, or copy or replication of that personal data. Where the controller has authorised a third party publication of personal data, the controller shall be considered responsible for that publication.

It should be noted that this latter paragraph was much stronger in the earlier drafts of the regulation: rather than requiring steps to be taken to inform third parties, the right was intended to make controllers take all reasonable steps to 
...ensure the erasure of any public Internet link to, copy of, or replication of the personal data relating to the data subject contained in any publicly available communication service which allows or facilitates the search of or access to this personal data.

This was much more of a 'seek and destroy' instruction - and Google and others understandably lobbied successfully to have it watered down to its current form. Article 17 is subject to the usual caveats and qualifications, ${ }^{8}$ including public interest in public health, historical, statistical and scientific research purposes, compliance with a legal obligation and, most pertinently perhaps, freedom of expression, as set out in Article 80:

"Member States shall provide for exemptions or derogations from the provisions on the general principles... ...for the processing of personal data carried out solely for journalistic purposes or the purpose of artistic or literary expression in order to reconcile the right to the protection of personal data with the rules governing freedom of expression."

The interpretation of these exemptions or derogations is critical to one aspect of the right to be forgotten - what constitutes 'literary expression', for example? Is any piece of text literary expression - or, to take it even further, as Jane Bambauer has done, should any form of data be considered 'speech', and thus literary expression? ${ }^{9}$ Conversely, does the inclusion of the word 'solely' mean that almost nothing is exempted, as it could be possible to find multiple purposes for almost any data - is an email literary expression, or communication, for example?

\section{Data or stories - and 'forgetting' or erasure?}

Though making these kinds of distinctions is difficult, there does seem to be a clear difference between something that can be viewed as relatively 'pure' data for example a web-user's browsing history - and something that is clearly a 'story', for example a newspaper article about an event. The latter is clearly 'expression' and should, in European Convention terms, engage Article 10. The former is generally never intended to be published or indeed seen by anyone except the user, and then only to navigate forward and backward, or to find websites previously visited. This demonstrates the difference between a right to be forgotten and a right to 'erasure'. Stories can potentially be forgotten, while data can be erased.

In a good deal of the discussion, particularly in the media, this differentiation is missed but it is crucial to the way that any right to be forgotten could work or should be understood. The Google Spain case is all about stories: events or records that have at least in some ways become 'public', and are 'searchable' via Google or some other search engine. Whilst this is important - and hence has been the focus of attention in the media and indeed in the courts, it only constitutes part of the data that is relevant here, and the part which might be the least appropriate for erasure, particularly in the light of Article 10 rights. Data that is not published, or has not yet been published, may be much more important - particularly in the post-Snowden context. This includes things like

\footnotetext{
${ }^{8}$ Set out in Article 17 (3) and (4) of the draft General Data Protection Regulation.

${ }^{9}$ In Bambauer, 'Is Data Speech?', Stanford Law Review, 2014, 66 (-), 62.
} 
the aforementioned browsing histories, profiles, individual search logs, meta data from many forms of communications, social mapping data, geolocation data, transaction records from online shopping, health data and many other kinds of data. These are forms of data that are not stories nor, generally, should be publically searchable, but which are critical in terms of privacy and autonomy. They are also precisely the kind of data that what was revealed by Snowden suggests are being gathered by the intelligence agencies and others.

Further, there are two different ways to deal with the data, in some ways reflected in the bifurcated name of the right: forgetting and erasure. Forgetting can be viewed as focusing on the viewer/reader of the data (the person who is being asked to forget) while erasure focuses on the data itself (which is what needs to be erased). Forgetting is about making the data or story difficult (or potentially impossible) to find, while erasure is about removing the data entirely. Erasure is therefore in general a stronger concept - because if data is genuinely erased, it cannot be found or viewed.

When these two dimensions (stories vs. data and forgetting vs. erasure) are set out in a table, four different scenarios can be seen, each of which presents different problems and requires different solutions.

Table 1

\begin{tabular}{|l|c|c|}
\hline \multirow{2}{*}{ Issues } & \multicolumn{2}{|c|}{ Type of data } \\
\hline Forgetting & Stories & Data \\
\hline Erasure & Stories made hard to locate & $\begin{array}{c}\text { Data made difficult to gather } \\
\text { or understand }\end{array}$ \\
& $\begin{array}{c}\text { Stories erased from the } \\
\text { Internet }\end{array}$ & Data deleted \\
\hline
\end{tabular}

Neither the stories-data axis nor the forgetting-erasure axis is simple. Though all stories are data, a story may exist in a number of different forms, each of which involves different data. Accordingly, though erasure is generally a stronger concept than forgetting, deleting one form of story-data will not necessarily delete the story itself, even if that form is the 'original' of the story, if that story exists in a different form.

Each of the different quarters of the table presents a different problem - and demands a different solution, as shall be seen below. The legal and technical approaches to each have been and should be different. The issue of forgetting stories, for example, is what many people think as a 'right to be forgotten' - and it is what the ruling in the Google Spain case relates to, and is the first one to be addressed. 


\section{Google Spain}

The Google Spain case concerned a Spanish man who found that when people searched for him on Google found an old story - an official notice in a newspaper from 1998 - about a property belonging to the man having been put up for auction in relation to his social security debts. The debts were settled before the auction, which never took place. The man originally sought to have the newspaper notice removed from the net: this was refused by the Spanish Data Protection Authority (AEPD), as the notice was part of the public record and the paper was under a legal obligation to report it. The man also asked Google to remove the links to that official notice: the AEDP agreed and placed an injunction on both Google Spain and Google Inc. Google appealed, the case was referred to the ECJ, who effectively ruled that Google did have to stop the link to the story from appearing in searches for the man's name.

It was a bold and far-reaching ruling and took observers by surprise by contradicting the earlier opinion of the Advocate General, who had effectively opined in Google's favour. The ECJ ruled very broadly, and not just in relation to the particulars of the Google Spain case. They said:

"As the data subject may, in the light of his fundamental rights under Articles 7 and 8 of the Charter, request that the information in question no longer be made available to the general public on account of its inclusion in such a list of results, those rights override, as a rule, not only the economic interest of the operator of the search engine but also the interest of the general public in having access to that information upon a search relating to the data subject's name".

Overriding the business imperative is one thing (though whether such a clear enunciation of the override would have been made against a European business is a moot point) but overriding the 'general public's right to information' is quite another. The question of whether one charter right can really override another is a difficult one. The balance between the two rights may be implicit - but perhaps it needs to be explicit. In this matter, as the whole history of the right to be forgotten has illustrated, the appearance and the emotional reaction to the words used makes a difference to how the law is implemented and understood. This is particularly pertinent here as one of the primary criticisms of the right to be forgotten has been that it might produce a chilling effect. That chilling effect depends on the perception more than the actual law, as most lay people cannot be expected either to know or to understand the nuances of the law.

This point implicitly acknowledges that, in practice, the economic interests of the search engines have been a crucial factor - perhaps the crucial factor - in the resistance to the right to be forgotten, for all that it has, in the US at least, been mostly expressed in terms of freedom of expression. ${ }^{10}$ Indeed, it can be argued that possible interference with economic interests have been the critical factor in the extensive lobbying and delays to the negotiation of the reform of the data protection regime as a whole.

\footnotetext{
${ }^{10}$ See the discussion of the competing interests in Bernal, 'The EU, the US and the Right to be Forgotten', in Serge Gutwirth, Paul De Hert, and Ronald Leenes (eds.), Computers, privacy and data protection- reloading data protection, 2014.
} 


\section{Academic shockwaves from Google Spain}

The ruling in Google Spain sent its own shockwaves though the Internet - not such profound and far reaching as those produced by the Snowden revelations, but in some ways more intense and more directed. The full impact of the ruling has still to be seen, but even in the first few weeks after the ruling things were beginning to happen. Those who had suggested that the right to be forgotten was already essentially implicit in the data protection regime had been proven correct - at least in the eyes of the ECJ, and at least to the extent that the 'hiding' of stories were concerned.

The Google Spain ruling brought back all the original criticisms of the right to be forgotten and added a few new ones. Academic commentators were remarkably active: more than 75 blog posts, newspaper articles or equivalents were written in the first month after the ruling, including pieces by such luminaries as MayerSchönberger, Morozov, Posner, Solove and Zittrain, as well as responses by the UK's ICO, the Article 29 Working Party and others. ${ }^{11}$ The Google Spain ruling seemed to focus the minds of those on both sides arguing about the right to be forgotten: the outpourings of opinion by academics in the immediate aftermath of the decision were extensive and multifaceted, but to a great degree reiterated the primary previous objections to the right.

These objections can broadly be divided into categories:

1) That the right to be forgotten interferes with freedom of expression to an excessive degree. Many of these criticisms, but far from all, emanate from the United States, where the First Amendment means that freedom of expression is generally assumed to 'trump' privacy or reputation rights except in extraordinary circumstances. These criticisms include the suggestion that the right to be forgotten will be used to rewrite history and spectres such as the alteration of photographs under Stalin's Soviet regime and the feeling that the likes of Berlusconi might wish to similarly airbrush their past have been regularly aired. Other examples used to make this point have included the example of the murderers of German actor Walter Sedlmayr attempting to have their criminal history removed from Sedlmayr's Wikipedia page - something which does indeed look like censorship or the rewriting of history. ${ }^{12}$

2) That the right to be forgotten is impractical, or cannot ever be made to work. The complexity of removal of information from the Internet is central to this objection - and the ability of Internet users to find ways around censorship and control, the Streisand Effect and so forth all feed into this. Closely related to this is the sense that suggesting that people have a right to be forgotten will raise false expectations and deceive people into acting with less care than they should. Google's response to the ruling, discussed below, could be argued to both strengthen and

\footnotetext{
${ }^{11}$ A compendium of academic commentaries to the Google Spain case has been compiled by Julia Powles and Jat Singh of Cambridge University, and may be found at http://www.cambridge-code.org/googlespain.html.

12 This case was central to Rosen's argument in his aforementioned piece in the Stanford Law Review Online: http://www.stanfordlawreview.org/online/privacy-paradox/rightto-be-forgotten.
} 
weaken this point depending on your perspective: they have already introduced a system that seemingly allows the right (in its limited form) to function, but at the same time this system seems to produce exactly the bad effects that opponents of the right to be forgotten predicted.

That the right to be forgotten will stifle the general freedom of the

Internet. This is a variant of a common suggestion that to take privacy into account restricts innovation, viewing data protection and related regulation as bureaucratic barriers to the businesses that create and stimulate the Internet. The extent to which this is a real objection is a little unclear: from a more libertarian (or specifically cyber-libertarian) perspective, any legislation restricts freedom and any attempt by conventional regulators is both undesirable and doomed to failure.

To these criticisms has been added an extra suggestion, building on the way that the Google Spain ruling seems to have been interpreted by Google: that a right to be forgotten places even more power in the hands of Google, as Google will, in the first instance at least, be the ones who determine whether or not a request for a link to a story to be removed will be honoured. This latter criticism has a degree of validity, though the extent to which Google already has this power and wields it - is a factor not so often mentioned by the critics of the right to be forgotten.

The validity of these criticisms to the initial proposals for the form of a right to be forgotten in the proposed reform to the data protection regime had been the subject of a good degree of academic analysis - but the extent to which this debate had remained unresolved can be seen by the sheer volume of opinion offered in the wake of the Google Spain verdict, to a significant degree repeating and reaffirming the prior positions of those involved. The Google Spain verdict has, however, made the situation much more urgent. This is no longer a primarily theoretical debate, but one that is being played out for real right now.

It has also changed the dynamics of the reform process: there was a sense that before Google Spain, the lobbying energies of the Internet giants, led by Google itself, were aiming not just at weakening the reform but delaying it or perhaps even killing it. ${ }^{13}$ After Google Spain, this appears very likely to change. The legal possibilities for Google to have the ruling reversed are very limited indeed, as the ruling was by the Grand Chamber of the CJEU. There is no obvious appeal process, though there might be a route to challenge particular examples through the European Court of Human Rights on Article 10 grounds. That, however, would be difficult and very likely to be slow. The data protection reform process might well be Google's best chance to free themselves from the apparent shackles and administrative burden that the ruling seemingly imposes, as a new data protection regime, with an explicitly stated right to erasure, could effectively override the Google Spain ruling. Rather than seeking to delay or block the reform, therefore, their efforts may be better directed to speed up the reform, so long as the right to erasure within it is expressed in a more limited form.

\footnotetext{
${ }^{13}$ See particularly the various blogs by Peter Fleischer discussed in footnote 3 above.
} 


\section{Google's response to the Google Spain ruling}

Google's response to the Google Spain ruling has been fast, somewhat surprising, and possible to read in a number of different ways. As they describe it in their 'FAQ' on the right to be forgotten:

"Since this ruling was published on 13 May 2014, we've been working around the clock to comply."14

Google's immediate response has a number of facets. Firstly, they have provided a 'web form' for people who wish to make an individual request, and say that they will evaluate each request individually. In the month following the ruling, Google have said that they received around 70,000 such requests: ${ }^{15}$ a large number, but in the context of Google's scale it is actually relatively small. In approximately the same period, Google received requests for the removal of more than 25 million URLs on the basis of copyright - hundreds of times more. ${ }^{16}$ Google has put together an expert 'advisory committee' to negotiate the issues, including Wikipedia cofounder Jimmy Wales, Oxford Professor of Information Ethics Luciano Floridi, UN Special Rapporteur for the Promotion and Protection of the Right to Freedom of Opinion and Expression of the UNHRC Frank La Rue. ${ }^{17}$ Secondly, Google have added a note to the search results for any individual name (other than a name of a public figure) that 'Some results may have been removed under data protection law in Europe'. Thirdly, Google have started to notify people (and in particular journalists) ${ }^{18}$ that some links to their stories have been deleted.

A number of things are apparent from Google's rapid response - and some are far less clear. Firstly, they have acted very fast, faster than any of the other search engines, though the Google Spain ruling applies equally to all. That in itself could be significant, as before the Google Spain ruling Google's tactics not just in this area but also in other dealings with the European Union seemed to be characterised more by slowness than speed. ${ }^{19}$ Secondly, the blocks that seem to have happened do not look immediately as though they fit within the categories immediately obvious from the Google Spain ruling: James Ball in the Guardian was notified about stories from as recently as $2011,{ }^{20}$ while Robert Peston of the BBC was notified about a story on as topical and in the public interest subject as

\footnotetext{
14 The FAQs are available under http://www.google.co.uk/policies/faq/.

15 Reported for example at http://www.theguardian.com/technology/2014/jul/03/google-right-to-be-forgottenlaw-uk-news-search-requests.

${ }^{16}$ According to Google's transparency report, accessed 09.07.2014, 25,649,607 URLs had been requested to be removed in the previous month. See http://www.google.com/transparencyreport/removals/copyright/. 17 See https://www.google.com/advisorycouncil/. ${ }^{18}$ Notably James Ball in the Guardian and Robert Peston of the BBC - see footnotes 20 and 21 respectively.

${ }^{19}$ For example in their negotiations over data retention periods for search logs, as discussed in Chapter 5 of Bernal, Internet privacy rights: rights to protect autonomy, 2014.

20 See http://www.theguardian.com/commentisfree/2014/jul/02/eu-right-to-beforgotten-guardian-google.
} 
the removal of a senior executive from a major bank. ${ }^{21}$ These are not old, or irrelevant stories, and nothing like the original story that was the subject of the Google Spain case. It looks, on the face of it, as though Google's initial response was to 'overblock': whether by clumsiness or in a more calculated response to help characterise the right to be forgotten as a form of censorship and a threat to freedom of expression is not easy to determine. Similarly, whether the alerts to journalists were clumsy or deliberately intended to inspire articles against the ruling is also unclear - it was notable that it appears that only UK journalists received such alerts rather than journalists in other EU states, though the Google Spain ruling applies throughout the EU. There has been more resistance to the right to be forgotten in the UK than other EU states, including a notable speech by Kenneth Clarke, then Lord Chancellor and Secretary of State for Justice. ${ }^{22}$

How this plays out over the months to come needs careful watching. It could be that Google are making a genuine albeit clumsy attempt to find a workable solution. It could also be that, as some critics of the right to be forgotten have suggested, that the right itself is fundamentally unworkable - or at least so difficult to make work in any meaningful fashion that the negatives outweigh the positives. Finally, it could be that this is just another calculated episode in Google's overall campaign against the right to be forgotten, and needs to be considered in the light of future negotiations over the right and how it can or could be incorporated in the reform of the data protection regime.

\section{Google Spain in the context of Snowden}

The connections between the revelations of Edwards Snowden and the Google Spain case are not obvious. One concerns government surveillance and data gathering, the other the unforgiving and 'unforgetting' nature of the Internet and in particular search. One concerns the protection of individuals from government intrusion, the other the protection of individuals from other individuals and from Internet businesses such as Google. There are, however, strong links between them, in at least two ways.

\section{Courts showing more privacy-awareness}

The first relates to the position that privacy holds in the minds of people. As noted above, governments, businesses, academics and advocates have all been caught up in the story - though the precise nature of what was uncovered by Snowden, how much of it is true as so forth remains unclear. What does appear clear is that the scale of surveillance - and specifically of data gathering - on the Internet undertaken by governments and their agencies is of a scale and scope that previously only conspiracy theorists would have contemplated. That has an impact on anyone concerned with privacy. In many ways the details of the surveillance and data gathering that is taking place may be less important than the perception. It is the perception that alters the behaviour of people, the reactions of companies and the governments and so forth.

\footnotetext{
${ }^{21}$ See http://www.bbc.co.uk/news/business-28130581.

22 His speech, from May 2011 can be found online at

http://www.justice.gov.uk/downloads/about/moj/our-ministers-

board/speeches/clarke-speech-data-protection-260511.doc.
} 
In particular, it may well have had an impact on the courts. In recent months there seems to have been a trend of courts - and the CJEU in particular - taking a stronger stance on privacy, getting closer to grips with the technology, and being willing to make bold, potentially controversial rulings that challenge powerful interest groups. Perhaps the strongest of these was the decision by the CJEU in April 2014 that the Data Retention Directive was invalid. ${ }^{23}$ In this case, as in the Google Spain case, the CJEU went further in the direction of supporting privacy than the Advocate-General's Opinion suggested. In the Data Retention example, the links to the Snowden revelations are much more direct than in Google Spain, as the Data Retention Directive concerns an aspect of mass surveillance, but in both cases the increased emphasis on the importance of privacy is highlighted in both the decision and the language used by the CJEU in the judgments. Other recent judicial decisions in other courts seem to show similar patterns: the Irish High Court in referring the Europe vs. Facebook case to the CJEU, ${ }^{24}$ the UK Supreme Court in its ruling over the disclosure of past criminal records in job applications, ${ }^{25}$ and even the US Supreme Court in its ruling over the need for warrants to search the contents of mobile phones. ${ }^{26}$

Whilst only the Data Retention invalidity and the Europe vs. Facebook case make direct reference to what was uncovered by Snowden, it may not be too much of a stretch to link the others to the increased awareness and understanding both of privacy and of technology that the Snowden revelations have brought about. That change of atmosphere is something that needs to be considered very carefully when looking at how we should address the right to be forgotten.

\section{Links between authorities and commercial organisations.}

One of the key aspects of what was revealed by Snowden is the relationship between the authorities and commercial organisations over surveillance. The PRISM programme, in particular, suggested that the NSA and others had direct access to the servers of commercial Internet companies such as Apple, Microsoft, Yahoo!, Facebook and Google. The way that this access worked, and the extent to which cooperation between the companies and the government agencies was willing rather than coerced has remained unclear, and given the nature of the subject it may well always remain unclear, but the implications of this and other related discoveries are direct. It appears a reasonable assumption that most of what is gathered and collected by commercial organisations for commercial purposes may well be accessible by government agencies for their own purposes.

This has a profound impact upon both how people - the customers of these commercial services - view and potentially use those services and upon the positions taken by the companies concerned in relation to government access to their data and to privacy more generally. Before the Google Spain ruling, Google had shown some distinct signs of changing their position in relation to privacy and Snowden appears to have played a significant part in bringing about that

\footnotetext{
${ }^{23}$ In Joined Cases C-293/12 and C-594/12

Digital Rights Ireland and Seitlinger and Others.

24 In Schrems vs. Data Protection Commissioner, [2014] IEHC 310.

${ }^{25}$ In $R(T) v$ SSHD [2014] UKSC 35.

${ }^{26}$ In 13-132 Riley v. California (06/25/2014).
} 
change. In the US what Snowden uncovered has made the government agencies look as though they were in some ways going against the ordinary people. As a consequence, if Google and others were not to be considered substantially to be working with the NSA - and hence against ordinary people - they needed to show that they would work for those ordinary people, and resisting the excessive surveillance requirements of the government agencies. That has meant being more aggressive in their pushes for 'transparency', and against overweening surveillance. Google is part of the 'Reform Government Surveillance' movement, ${ }^{27}$ for example. It has also meant more of an embrace of privacysupportive technologies such as encryption - for example in email connections to servers. ${ }^{28}$

Google and others are also trying to ensure that people differentiate between the kinds of surveillance and potentially privacy-invasive practices engaged in by commercial organisations and those performed by the authorities, a point emphasised by some of the privacy advocacy groups, who created their own alternative to the 'Reform Government Surveillance' movement: 'Reform Corporate Surveillance'. As Bruce Schneier explained on the Reform Corporate Surveillance website:

“The NSA didn't wake up and say, 'Let's just spy on everybody.' They looked up and said, 'Wow, corporations are spying on everybody. Let's get ourselves a copy.'"29

It is difficult to disagree with Schneier. Indeed, this is the logic applied by Hogan, J in the Europe vs. Facebook case, which hinges on the way that the Safe Harbor agreement might not protect data held by Facebook in the US from access by US authorities. If the data were not being gathered by the commercial organisations in the first place, the authorities would not be able to gain access to it, directly or indirectly, through legal or illegal means. If people are to be protected from intrusion into their private lives by authorities, whether from their own governments or others, intrusions, data gathering and data holding by commercial organisations need to be taken into account. The referral of the Europe vs. Facebook case to the CJEU is based on that understanding - and as awareness of the nuances of the relationship between privacy and technology increases, other courts may well take similar views.

\section{Contrasting the Google Spain and Snowden issues}

Though there are similarities and connections between the issues that underlie the concern raised by Snowden and the Google Spain case, there are also qualitative differences. Considering again the bifurcated nature of the right to be forgotten, as set out in Table 1 above, there are two aspects to the right: the 'forgetting' and the 'erasure'. Google Spain ruled clearly on the 'forgetting' element, but not on the erasure. When considering Snowden, however, the

\footnotetext{
${ }^{27}$ https://www.reformgovernmentsurveillance.com.

${ }^{28}$ See for example http://googleblog.blogspot.co.uk/2014/03/staying-at-forefront-ofemail-security.html in response to the MUSCULAR system, see http://www.washingtonpost.com/world/national-security/nsa-infiltrates-links-toyahoo-google-data-centers-worldwide-snowden-documentssay/2013/10/30/e51d661e-4166-11e3-8b74-d89d714ca4dd_print.html.

${ }^{29}$ See at http://reformcorporatesurveillance.com.
} 
erasure part of the right may be more significant, in two ways. Firstly, on the assumption (which may be false) that data is not automatically gathered on creation, erasure could increase the chances that this data is not ever 'communicated' and hence added to the NSA's stockpiles. Secondly, and perhaps more importantly, the development of the right to erasure would encourage the development of lean business models that do not rely so heavily on the accumulation of data. ${ }^{30}$

However, what people often want in relation to either commercial organisations or other individuals (as opposed to authorities) is the forgetting aspect of the right. That is, as in the Google Spain case itself, their real concern isn't permanent erasure of the data, or the rewriting of history, but that what people (or organisations) find out about them on an ordinary search or relatively cursory investigation is not skewed or misleading as a result of the over-prioritisation of old or irrelevant information. The UK Supreme Court decision in R (T) v SSHD [2014] UKSC 35, over the disclosure of past criminal convictions in job applications, is exactly on that point. This does not require the rewriting of history, or the erasure of records, but what Selinger and Hartzog have referred to as 'obscurity'. 31

One potentially positive aspect of the Google Spain ruling is that it might encourage Google to develop algorithms that downplay older, less 'relevant' stories - the kind that should be 'forgotten' - so as to avoid too many applications for removal. This, as well as helping Google could, in effect, improve the chances of people achieving the kind of obscurity that underlies the Google Spain case. This has parallels to the way that the erasure part of the right to be forgotten could encourage the development of leaner business models. It also could be argued to begin to address the somewhat vague objection to the right to be forgotten that it stifles Internet freedom.

\section{The Right to be Forgotten in the post-Snowden era}

To look at where this leaves us and what the prospects are for the future, we must look at what has changed since the Snowden revelations, and at what has not changed. One of the most important things that seems to have changed is our perception of vulnerability - and with it our understanding of the importance of privacy. The idea that privacy really didn't matter to people, that in Mark Zuckerberg's words it was 'no longer a social norm', did not ever have as much strength as advocates of transparency and 'publicness' suggested - but it has even less now. Privacy matters, and that more people, businesses and governments realise that has a connection to Edward Snowden. Privacy has political value, ethical value, legal value and potentially commercial value, as businesses seek to portray themselves as privacy-friendly to gain competitive advantages.

\footnotetext{
${ }^{30}$ As argued in Bernal, 'A right to delete?', European Journal of Law and Technology, 2014, 2 (2).

${ }^{31}$ See for example Selinger/Hartzog, 'Obscurity and Privacy', in Routledge Companion to Philosophy of Technology, Pitt and Shew eds., forthcoming 2014.
} 
Many things, however, have not changed. The extent to which businesses gather data for their own purposes shows little sign of abating. The primary concerns of the big Internet companies in the light of the Snowden revelations have been to suggest that they are trying to limit the extent to which the government agencies have access to their data and systems, and to differentiate their kind of surveillance and data gathering (which they say is to help people) and the governments' kinds of surveillance and data gathering (which is an unwarranted intrusion).

What also has not changed in relation to the right to be forgotten is the concern over freedom of expression - to the extent that it was real in the first place, rather than a cover for a wish to protect business models. This needs to be taken seriously.

\section{Workable solutions and meeting the challenges}

How, then, can workable solutions be found, solutions that meet the genuine challenges made and address the issues that continue to be raised. A starting point is to return to the splitting of the issues as set out in table 1 above:

Table 2

\begin{tabular}{|l|c|c|}
\hline Solutions & \multicolumn{2}{|c|}{ Type of data } \\
\hline Forgetting & $\begin{array}{c}\text { Stories } \\
\text { Obscurity - and the right as } \\
\text { suggested in Google Spain } \\
\text { Erasure }\end{array}$ & $\begin{array}{c}\text { Data obscurity - stronger } \\
\text { encryption, leaner business } \\
\text { models, more distance } \\
\text { between businesses and } \\
\text { authorities }\end{array}$ \\
\hline & $\begin{array}{c}\text { No general right appropriate - } \\
\text { freedom of expression } \\
\text { overrides. }\end{array}$ & $\begin{array}{c}\text { The right to erasure - } \\
\text { enforcing data minimisation }\end{array}$ \\
\hline
\end{tabular}

Only the stories really engage freedom of expression. If the kind of right set out in the Google Spain ruling can be more suitably defined, it could provide an appropriate 'right to obscurity'. Defining it suitably is a challenge - but one that the data protection reform process needs to embrace. In Google Spain, as many of the commentators have pointed out and to an extent the reaction of Google has highlighted, too much power is in the hands of Google and the other search 
engines. Guidelines as to where the balance should be placed between freedom of expression and privacy need to be more explicit and clearer. What constitutes 'old' and 'irrelevant', for example, needs to be discussed, agreed and properly set out.

In terms of erasure rather than obscurity of stories, the balance should be firmly in the direction of freedom of expression and of information. The permanent erasure of a story quite rightly raises significant issues of censorship and the rewriting of history in the way that a limited form of obscurity is not. To establish a general right to the erasure of stories seems inappropriate. There may be cases where it is suitable, but these will be very rare and deserving of individual consideration. Moreover, existing law such as the law of defamation may well cover a significant proportion of those cases where erasure is requested.

With the kind of data for which freedom of expression does not in any meaningful sense come into play, the balances to be made are different. Rather than balancing privacy with freedom of expression, the balance is to be made with the right to carry on a business - and from a human rights perspective that means that, in general and as acknowledged in the Google Spain ruling, the right to a private life should remain paramount. In order to enable this in a practical sense, for obscurity of data (for example from government intrusion) the kinds of moves already being made by businesses to make encryption the default and to require stronger authorisation for government access is a starting point. For proper obscurity this needs extending to data sharing between businesses - and ensuring that the data protection reform goes through in a robust and enforceable form is the key to this. Ultimately, however, a genuine right to erasure of data, where freedom of expression does not come into play, still appears to be a key tool, as part of an encouragement and a possible enforcement for data minimisation.

This kind of a solution would address, at least insofar as it is possible to address, the issue of maintaining an appropriate balance between privacy and freedom of expression. Whether it is workable is another question, and one that cannot be answered definitively. Google's implementation attempts so far have been clumsy at best - but the process might be one that can be fine-tuned into something practical. Given that Google deal with far more copyright takedown requests, the scale should not be insurmountable - and the speed with which Google put the system in place suggests that with more time, more accuracy could be attained. With better guidelines and more accountability, the seeming increase in power for Google would be reduced - and it must be remembered that to a great extent they already have the power to manipulate search results, so this complaint against the right to be forgotten is to an extent a straw man. Similarly, the complaint that the right to be forgotten reduces Internet freedom is largely illusionary: the kind of freedom suggested does not exist even now. The influence and control wielded by Google themselves and the mass media operators who are some of the most vocal opponents of the right to be forgotten already means that this freedom, in Article 10 terms, is not in the hands of ordinary people. The right to be forgotten, if better implemented, would primarily mean a shift in where the power and control is held, not an increase in that power and control. 


\section{Data Protection Reform}

All this leads to the need to focus on data protection reform. The process has been slow so far, almost tortuously so, but the combination of the revelations of Edward Snowden and the Google Spain ruling makes that reform urgent. Amongst the many things that have been learned as a result of what Snowden leaked, one of the most important is the inadequacy of the existing regime, both theoretically and pragmatically. A new, updated regime is critical, and it needs to have the tools and the strength to be able to hold the big commercial Internet companies to account - and to encourage them to find ways to provide the kind of protection and privacy that people need. The apparent emboldening of the European courts adds to this urgency, also both from a theoretical and a practical perspective. Both the declaration of invalidity of the Data Retention Directive and the Google Spain judgment exceeded the expectations of privacy advocates and indeed the opinions of the Advocates General. Both are significant in their impact and unequivocal in their direction: privacy matters not just to privacy advocates but to the courts. This emboldening could have a further impact: strengthening the hand of those pushing for a strong new regime. It also adds support to the arguments of those who suggest the right to be forgotten is an expression of the basic principles of data protection, and hence should be included within the reform.

Conversely, the strength and at the same time potential unworkability and burdensome nature of the Google Spain ruling should add urgency to the cause of those who have hitherto opposed the existence of the right to be forgotten. As the right already exists - in a form particularly burdensome to precisely those companies who have been lobbying against the right - they must perform a volte-face. If they want to make the right more workable and less onerous, they must start pushing for the reform to happen sooner rather than later. From a practical perspective, the strength of the Google Spain ruling makes it seem less likely than ever that the idea of a right to be forgotten will be dropped from the reform, no matter how much lobbying takes place in the opposite direction. The question seems to be much more what form that right takes and whether it can be made workable. That is a challenge that both lawyers and technologists need to face up to. 